\title{
Determination of Load Bearing Capacity of Two Nigerian Fresh Tomato Varieties
}

\author{
Gloria Nwakaegho Elemo ${ }^{2}$, Phillip Adeleke Adepoju ${ }^{1}$, James Iwebuno Mordi ${ }^{2, *}$, Adeteju Oluwafunmilayo \\ Longe $^{1}$ and Olubukola Esther Abatan ${ }^{1}$ \\ ${ }^{1}$ Food Technology Department; Lagos State Polytechnic \\ Ikorodu, Lagos, Nigeria \\ ${ }^{2}$ Food and Analytical Dept; Federal Institute of Industrial Research, Oshodi (FIIRO) \\ Lagos, Nigeria \\ *Corresponding author's email: mordi.james [AT] fiiro.gov.ng
}

\begin{abstract}
Tomato cultivars - Roma and Ibadan local (Ibadan L) at stage five degree of ripeness were subjected to rupture test by application of varying weights of $1-2.5 \mathrm{~kg}$ to determine the time it takes to rupture the fresh tomato samples. Roma cultivar of $23 \mathrm{~g}$ size took $28 \mathrm{~min}$ and $1.2 \mathrm{~min}$ to rupture under $1 \mathrm{~kg}$ and $2.5 \mathrm{~kg}$ weight respectively while the same variety of $76 \mathrm{~g}$ size took $90 \mathrm{~min}$ and $50 \mathrm{~min}$ to rupture under $1 \mathrm{~kg}$ and $2.5 \mathrm{~kg}$ weight applied respectively. For Ibadan Local (Ibadan L) of $23 \mathrm{~g}$ size, it took $17 \mathrm{~min}$ and $0.67 \mathrm{~min}$ to rupture under $1 \mathrm{~kg}$ and $2.5 \mathrm{~kg}$ weight respectively while that of $76 \mathrm{~g}$ size took $70 \mathrm{~min}$ and $15 \mathrm{~min}$ to rupture respectively. This result showed that for any variety, the bigger the size of the fruit, the longer the time taken for the fruit to rupture under any particular load applied. The extent fresh tomatoes are able to keep and maintain freshness in their ripen state depends on their load bearing capacity.
\end{abstract}

Keywords--- Tomatoes varieties, Applied weight, Load bearing capacity

\section{INTRODUCTON}

Tomato (Lycopersicon esculentum) constitutes one of the most important supplementary sources of minerals and vitamins in human diet. The estimated annual production of fresh tomatoes in Nigeria was 1.7 million tons of about 129.65 million tons of the world's tomato production [1]. This represents about $1.3 \%$ of world tomato production output. In addition Nigeria imported processed tomato paste to the tune of 105,000 metric tons valued at over $\$ 16$ billion between 2009 and 2010 [2]. This constitutes a huge drain on the country's scarce foreign exchange. A loss of 50\% has been reported to occur between harvesting, transportation and consumption of fresh tomatoes [3]. Limited shelf life and losses in quality have been identified as the major problems faced in the marketing of fresh tomatoes [4].

Refrigeration and cold storage system often used in advanced and temperate countries for fresh produce storage may not be suitable for use in Nigeria due to their high cost of energy requirement. Also most tropical fruits and vegetables like tomatoes are subject to chilling injury when stored at refrigeration temperatures [5]. Since tomato consumption in Nigeria is mainly in the fresh form, it is essential that they are stored in a system that can maintain their freshness until when consumed without any noticeable physiological disorder.

According to reports [6] tomato cultivars with thick skin are generally more resistant to handling practices, storage diseases or physiological disorders so are usually preferred for storage in their fresh forms. Firmness of tomatoes is determined by consumers using finger feel and under other conditions slicing characteristics which tend to reflect quality via the degree of softness observed. In recent years, much popular concern has been expressed regarding the deteriorating quality of fresh tomatoes available in the Nigerian consumer market $[5,7,8]$. Tomato fruit quality has been reported to comprise of subjective and objective attributes [9]. Appearance, colour and flavor are primarily subjective tomato quality attributes which influence consumer acceptability while fruit acidity, $\mathrm{pH}$, total solids, pigment content etc are objective attributes that can be quantified and related to quality [10] carried out simulated transit studies on tomatoes: effects of compressive load, container, vibration and maturity on mechanical damage while [11] studied the effect of evaporative cooler environment on the visual qualities and storage life of fresh tomatoes. The extent fresh tomatoes are able to stay in these systems will depend on their ability to withstand pressure and their load bearing capacity. Hence, the objective of this study is to determine the effect of applied weight on the load bearing capacity of fresh tomato varieties. 


\section{MATERIALS AND METHODS}

\subsection{Procurement of fresh tomatoes}

Fresh tomatoes of the "Roma" and Ibadan Local (Ibadan L) cultivars at stage 5 (full red colour) [12] were obtained from the retail fruit stands of Mile 12 market in Lagos, Nigeria

\section{METHOD OF STORAGE}

A modified method [11] was used for the storage of fresh tomatoes prior to the testing. Tomato fruits free of any visible defects were washed carefully under tap water and allowed to drip dry at room temperature conditions. These samples were unpackaged and laid out in the laboratory bench for testing. Each tomato fruit of a particular cultivar was weighed and sorted according to sizes and their individual weights were noted.

\section{TEST FOR THE LOAD BEARING CAPACITY}

A modified method [10] was used for this study. Tomatoes of the same cultivar were sorted according to sizes and their weights varying from $23,28,39,52,63,72,74$, and $76 \mathrm{~g}$ were noted. The control compression machine mode (CAT T104) of load varying from $1 \mathrm{~kg}, 1.5 \mathrm{~kg}, 2.0 \mathrm{~kg}$, and $2.5 \mathrm{~kg}$ was used to compress these tomatoes and the time taken for each tomato to rupture was noted.

\section{RESULTS}

The results of the time taken for the Roma tomato sample of the same weight/ sizes to rupture under varying weights of $1.0-2.5 \mathrm{~kg}$ are shown in Table 1 . Table 2 shows the result of the time taken for the Ibadan local tomato sample of the same weight/ sizes to rupture under varying weights of $1.0-2$. From Figs. 1 and 2, it is clear that a relationship exists between the weight of tomato and the time taken to rupture under different applied weights. It can be seen from the graphs that the time of rupture for both tomato varieties depend on the load applied. Therefore, to prolong the time of rupture and extend the freshness of tomato, the tomatoes maybe sorted to size before packaging or a new form of package designed. This result has showed that as currently done in which baskets are used to transport fresh tomatoes from production centres in Northern Nigeria to the Southern part of the country; the tomatoes at the bottom tend to rupture faster compared to those at the top. To avoid this, tomatoes of smaller sizes should be at the top while those of bigger sizes are at the bottom. It can be suggested from this result, that wooden flat boxes or crates should be used in order to avoid tomatoes from resting directly on themselves and as well reduce the rate of rupturing of tomatoes before getting to the final consumers.

\section{DISCUSSION}

The results of the time taken for the Roma tomato sample of the same weight/ sizes to rupture under varying weights of $1.0-2.5 \mathrm{~kg}$ are shown in Table 1. Table 2 shows the result of the time taken for the Ibadan local tomato sample of the same weight/ sizes to rupture under varying weights of $1.0-2$. The results showed that for any one variety under varying load that the time taken for the tomato to rupture has a direct relationship with the size of the fruit. It was observed that for any variety, the bigger the size of the fruit, the longer the time taken for the fruit to rupture under any particular load applied. Moreso, the bigger the applied load $(\mathrm{kg})$ for the same size of tomatoes, the shorter the time taken for the tomato to rupture. These results are in agreement with the findings of earlier workers [10].

From Figs. 1 and 2, it is clear that a relationship exists between the weight of tomato and the time taken to rupture under different applied weights. It can be seen from the graphs that the time of rupture for both tomato varieties depend on the load applied. Therefore, to prolong the time of rupture and extend the freshness of tomato, the tomatoes maybe sorted to size before packaging or a new form of package designed. This result has showed that as currently done in which baskets are used to transport fresh tomatoes from production centres in Northern Nigeria to the Southern part of the country; the tomatoes at the bottom tend to rupture faster compared to those at the top. To avoid this, tomatoes of smaller sizes should be at the top while those of bigger sizes are at the bottom. It can be suggested from this result, that wooden flat boxes or crates should be used in order to avoid tomatoes from resting directly on themselves and as well reduce the rate of rupturing of tomatoes before getting to the final consumers.

\section{REFERENCES}

1. FAOSTAT (2008) Faostat database. Available from http://faostat. Fao.org

2. Olufolaji, O. O. (2012) Prospects and Challenges of developing tomato varieties for production and processing in Nigeria. A Keynote paper delivered at the Raw Material Research and Development Council (RMRDC) NIRAM Expo 2012 Organized by RMRDC on $13^{\text {th }}-15^{\text {th }}$ November, 2012 at De Blue Roof, LTV Event Centre Agidingbi, Lagos. 
3. Aworh OC and Olorunda AO (1981) Towards reducing postharvest losses of perishable fruits and vegetables in Nigeria. Proc. National Conf. in Agric. Port Harcourt, Nigeria

4. Bhowmik SR and Pan JC (1992) Shelf life of matured green tomatoes stored in Controlled atmosphere and high humidity. Journal Food Sci. No 4, pp 948 - 953.

5. Olorunda (1987) Postharvest handling of fruits and vegetables in the Nigerian Marketing System. Procs of $1^{\text {st }}$ National AERLS, Home Economics Annual Workshop, ABU, Zaria $20-24^{\text {th }}$ July, pp $15-30$.

6. Goose PG and Binsted R (1973) Tomato paste and other tomato products. Food Trade Press Ltd, London.

7. Aworh OC, Olorunda AO and Akhuemonkhan IA (1982) Effects of postharvest handling on quality attributes of tomatoes in the Nigerian Marketing System. Food Chemistry, 10, 49 - 54.

8. Olorunda AO and Aworh OC (1983) A quantitative assessment of postharvest losses of perishable fruits and vegetables. Nigerian Journal Science. Vol 27 No 1 \& 2, pp 41 - 49.

9. Kearney NS and Coffey DL (1983) The influence of postharvest handling on tomato quality. Postharvest Institute for Perishables. University of Idaho Library, Moscow ID 83843, USA Vol 23, Oct - Nov - Dec.

10. Olorunda AO and Tung MA (1985) Simulated transit studies on tomatoes: Effects of compressive load, container, vibration and maturity on mechanical damage. Journal of Food Technology 20, $669-678$.

11. Mordi JI and Olorunda AO (2003) Effect of Evaporative Cooler Environment on the Visual Qualities and Shelf life of fresh Tomatoes. Journal of Food Sci. Technol Vol. 40, No. 6 pp $587-591$.

12. Winsor GW, Davies JN, Massey DM (1962) Composition of tomato fruit 111 - Juices from whole fruit and locules at different stages of ripeness. J Sci Food Agric 13:108 - 115.

Table 1: Time (min) of Rupture of Tomato (Roma variety) under varying weight

\begin{tabular}{|c|c|c|c|c|}
\hline \multirow[b]{2}{*}{ Weight of tomato } & \multicolumn{4}{|c|}{ Applied Load (kg) } \\
\hline & 1.0 & 1.5 & 2.0 & 2.5 \\
\hline $23 \mathrm{~g}$ & $28 \mathrm{~min}$ & $25 \mathrm{~min}$ & $10 \mathrm{~min}$ & $1.2 \mathrm{~min}$ \\
\hline $28 \mathrm{~g}$ & $32 \mathrm{~min}$ & $29 \mathrm{~min}$ & $13 \mathrm{~min}$ & $3.5 \mathrm{~min}$ \\
\hline $39 \mathrm{~g}$ & $41 \mathrm{~min}$ & $32 \mathrm{~min}$ & $19 \mathrm{~min}$ & $5 \mathrm{~min}$ \\
\hline $52 \mathrm{~g}$ & $55 \mathrm{~min}$ & $36 \mathrm{~min}$ & $25 \mathrm{~min}$ & $7 \mathrm{~min}$ \\
\hline $63 \mathrm{~g}$ & $59 \mathrm{~min}$ & $40 \mathrm{~min}$ & $40 \mathrm{~min}$ & $27 \mathrm{~min}$ \\
\hline $72 \mathrm{~g}$ & $83 \mathrm{~min}$ & $46 \mathrm{~min}$ & $49 \mathrm{~min}$ & $33 \mathrm{~min}$ \\
\hline $74 \mathrm{~g}$ & $87 \mathrm{~min}$ & $72 \mathrm{~min}$ & $55 \mathrm{~min}$ & $39 \mathrm{~min}$ \\
\hline $76 \mathrm{~g}$ & $90 \mathrm{~min}$ & $79 \mathrm{~min}$ & $60 \mathrm{~min}$ & $50 \mathrm{~min}$ \\
\hline
\end{tabular}


Table 2: Time (min) of Rupture of Tomato (Ibadan Local variety) under varying weight

\begin{tabular}{llccc}
\hline & \multicolumn{3}{c}{ Applied Load (kg) } \\
Weight of tomato & 1.0 & 1.5 & 2.0 & 2.5 \\
\hline $23 \mathrm{~g}$ & $17 \mathrm{~min}$ & $12 \mathrm{~min}$ & $3 \mathrm{~min}$ & $0.6 \mathrm{~min}$ \\
$28 \mathrm{~g}$ & $20 \mathrm{~min}$ & $18 \mathrm{~min}$ & $6 \mathrm{~min}$ & $1 \mathrm{~min}$ \\
$39 \mathrm{~g}$ & $25 \mathrm{~min}$ & $20 \mathrm{~min}$ & $8 \mathrm{~min}$ & $1.5 \mathrm{~min}$ \\
$52 \mathrm{~g}$ & $30 \mathrm{~min}$ & $23 \mathrm{~min}$ & $12 \mathrm{~min}$ & $1.8 \mathrm{~min}$ \\
$63 \mathrm{~g}$ & $38 \mathrm{~min}$ & $28 \mathrm{~min}$ & $25 \mathrm{~min}$ & $5 \mathrm{~min}$ \\
$72 \mathrm{~g}$ & $40 \mathrm{~min}$ & $31 \mathrm{~min}$ & $29 \mathrm{~min}$ & $8 \mathrm{~min}$ \\
$74 \mathrm{~g}$ & $51 \mathrm{~min}$ & $50 \mathrm{~min}$ & $32 \mathrm{~min}$ & $10 \mathrm{~min}$ \\
$76 \mathrm{~g}$ & $70 \mathrm{~min}$ & $51 \mathrm{~min}$ & $48 \mathrm{~min}$ & $15 \mathrm{~min}$ \\
\hline
\end{tabular}

\section{LEGEND TO FIGURES:}

Figure 1: Graph of time of rupture (mins.) against weight of samples under different applied weights (Roma cultivar)

Figure 2: Graph of time of rupture (mins.) against weight of samples under different applied weights (IbadanL cultivar) 


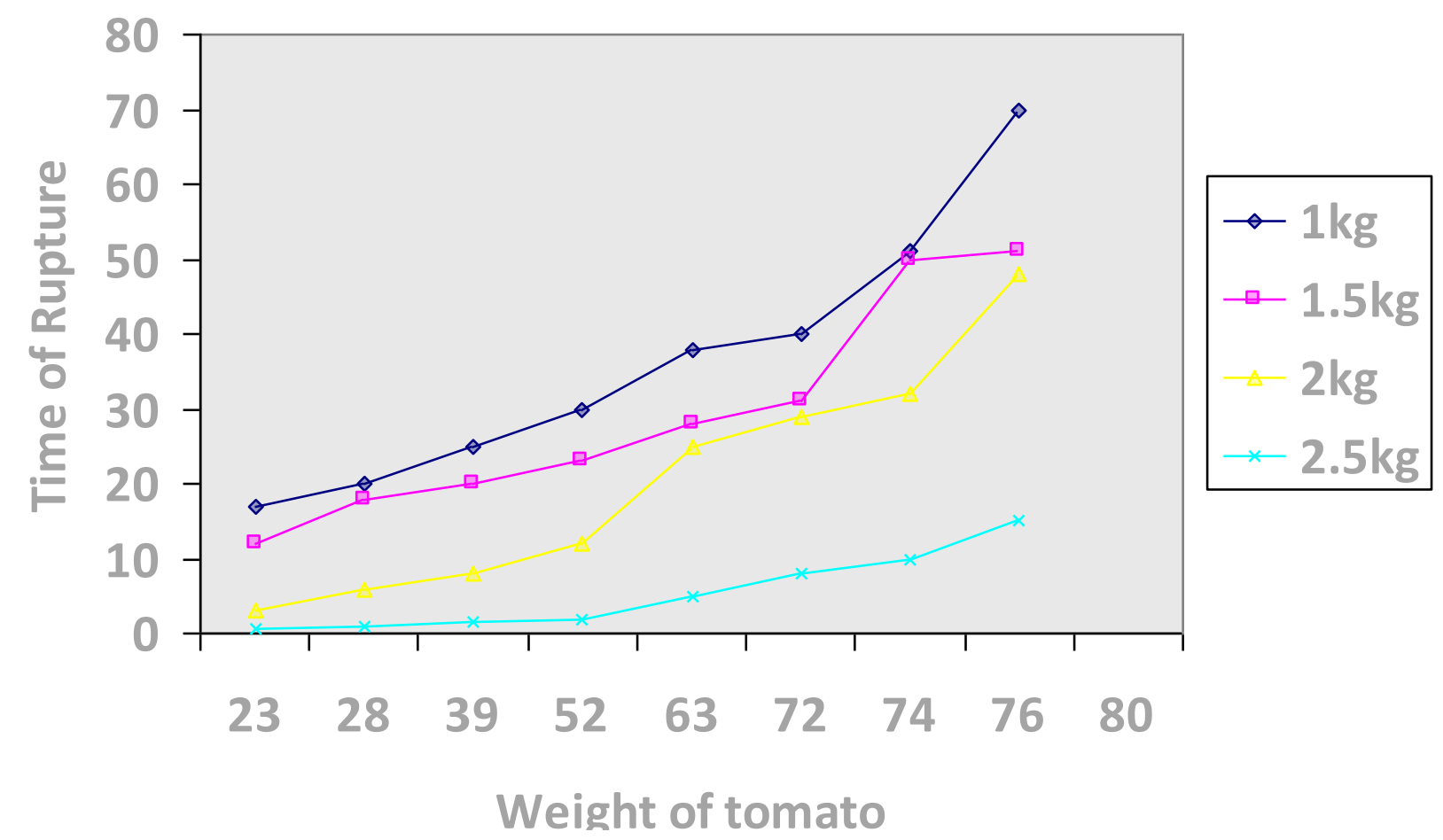

Figure 1: Time of rupture (min) against weight of samples under varying weights (Roma cultivar)

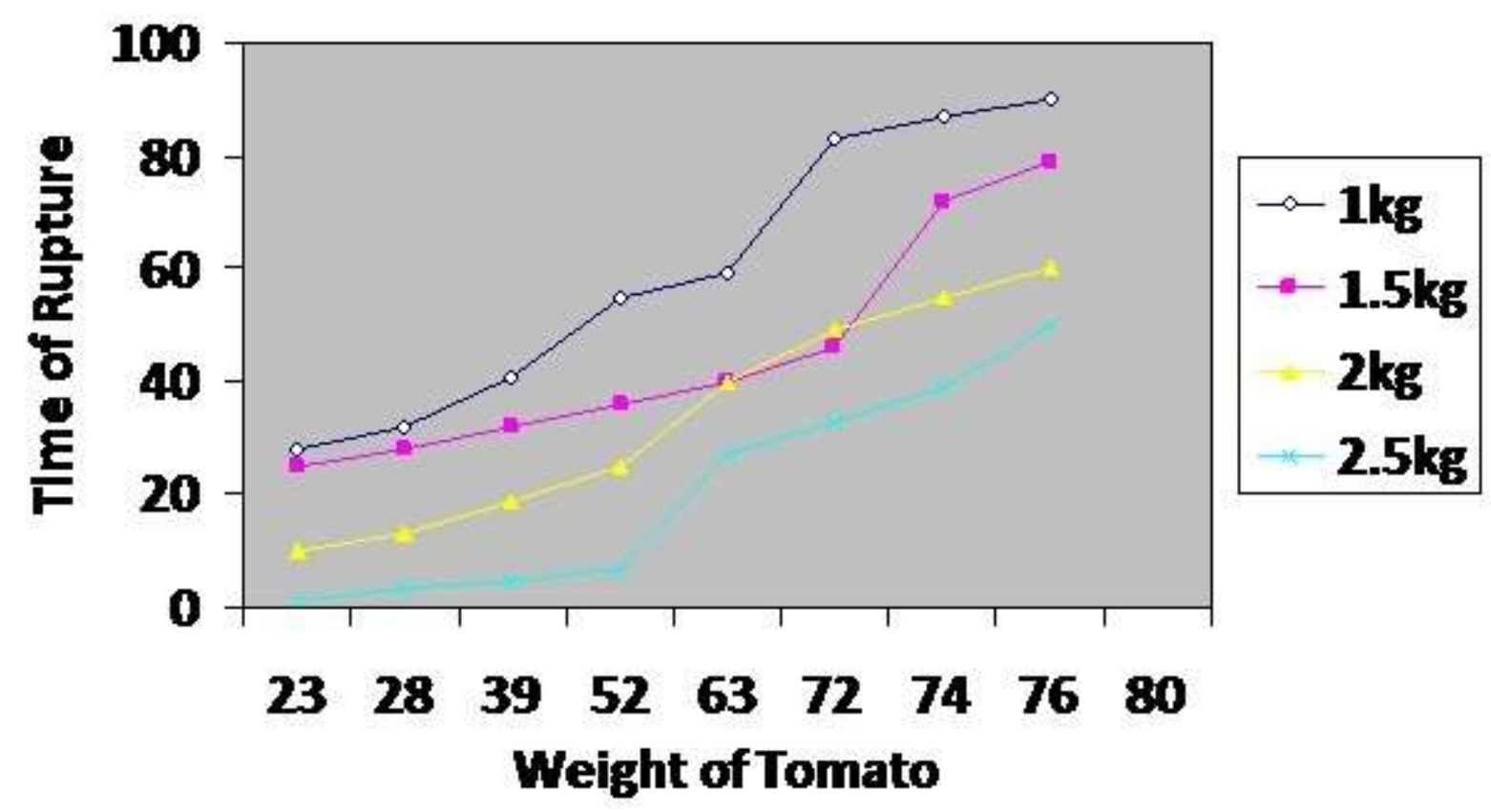

Figure 2: Time of rupture (min) against weight of samples under varying Weights (IbadanL cultivar) 